\title{
Respostas dos exercícios
}

\section{Tests answers}

Danilo Tadao Wada ${ }^{1}$ (D), José Antonio Hiesinger Rodrigues ${ }^{1}$, Marcel Koenigkam Santos² (D)

Seguem as respostas aos exercícios (material complementar) dos textos de estudo dirigido do simpósio de Radiografia Simples do Tórax.

1. Médico assistente da disciplina de Radiologia Torácica e Cardiovascular. Centro de Ciências das Imagens e Física Médica, Hospital das Clínicas da Faculdade de Medicina de Ribeirão Preto da Universidade de São Paulo, Ribeirão Preto (SP), Brasil.

2. Docente responsável pela disciplina de Radiologia Torácica e Cardiovascular. Fundação de Apoio ao Ensino, Pesquisa e Assistência do Hospital das Clínicas da Faculdade de Medicina de Ribeirão Preto da Universidade de São Paulo (FAEPA), Ribeirão Preto (SP), Brasil.

\M Danilo Tadao Wada. Avenida Bandeirantes, 3900 - Campus Universitário. CEP: 14049-900. Ribeirão Preto SP, Brasil. dwada@hcrp.usp.br | Recebido em: 17/02/2019 | Aprovado em: 26/04/2019 


\section{TEXTO 1}

\section{ASPECTOS TÉCNICOS E ROTEIRO DE ANÁLISE DA RADIOGRAFIA DE TÓRAX}

1. Em relação às incidências do $\mathrm{RX}$ de tórax, correlacione:
A. Protocolo padrão
D. Suspeita de nódulo no ápice do pulmão
B. Para avaliar derrame pleural
E. Avaliação de aumento do átrio esquerdo
C. Paciente acamado ou de difícil mobilização

\section{Resposta correta:}

(C) $A P$

(B) Decúbito lateral com raios horizontais

(D) Apicolordótica

(A) PA e perfil

(E) Obliquas

2. O RX de tórax realizado em expiração máxima pode ajudar em que situações?

Resposta correta: Na suspeita de pneumotórax pequeno e aspiração de corpo estranho.

3. O que há de errado com esta radiografia de tórax em relação à técnica de aquisição da imagem? O que pode ser feito para melhorar?

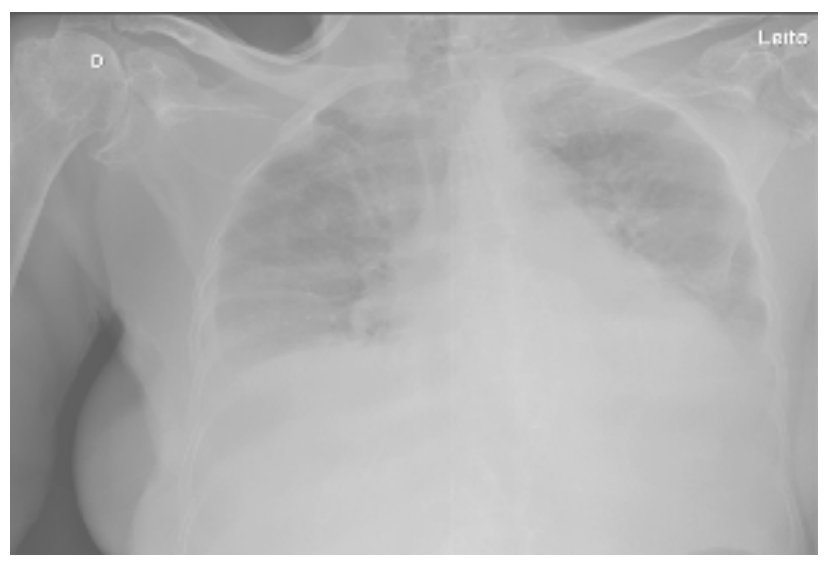

Resposta correta: Grafia em AP, pouco penetrada, pouco inspirada e paciente não centrado. Tentar repetir em PA, com maior dose de radiação, melhor inspiração e centrar o paciente no filme.

4. Como identificamos que um exame de RX de tórax realizado em PA e perfil está adequadamente centrado?

Resposta correta: As bordas mediais das clavículas têm a mesma distância para o centro da coluna dorsal.

5. Qual das alternativas abaixo não faz parte de um relatório de RX de tórax normal?
a) Estruturas ósseas íntegras
d) Índice cardiotorácico dentro da normalidade
b) Trama vascular pulmonar normal
e) Linfonodos mediastinais de aspecto habitual

c) Ausência de opacidades pulmonares

\section{Resposta correta: e}




\section{TEXTO 2}

\section{ANATOMIA NORMAL DA RADIOGRAFIA DE TÓRAX}

1. Qual região anatômica representa o principal indicador de doença pleural no RX de tórax?
a) Sulco superior
d) Seio costofrênico
b) Janela aortopulmonar
e) Recesso ázigo-esofágico

c) Seio cardiofrênico

\section{Resposta correta: $d$}

2. Qual a diferença entre os brônquios principais (centrais) a direita e a esquerda?

Resposta correta: à direita o brônquio fonte é curto e verticalizado, enquanto à esquerda o brônquio fonte é longo e horizontalizado. Apenas à direita há o brônquio intermédio, após a origem do brônquio lobar superior direito.

3. Nomeie as estruturas anatômicas apontadas (A, B, C e D).

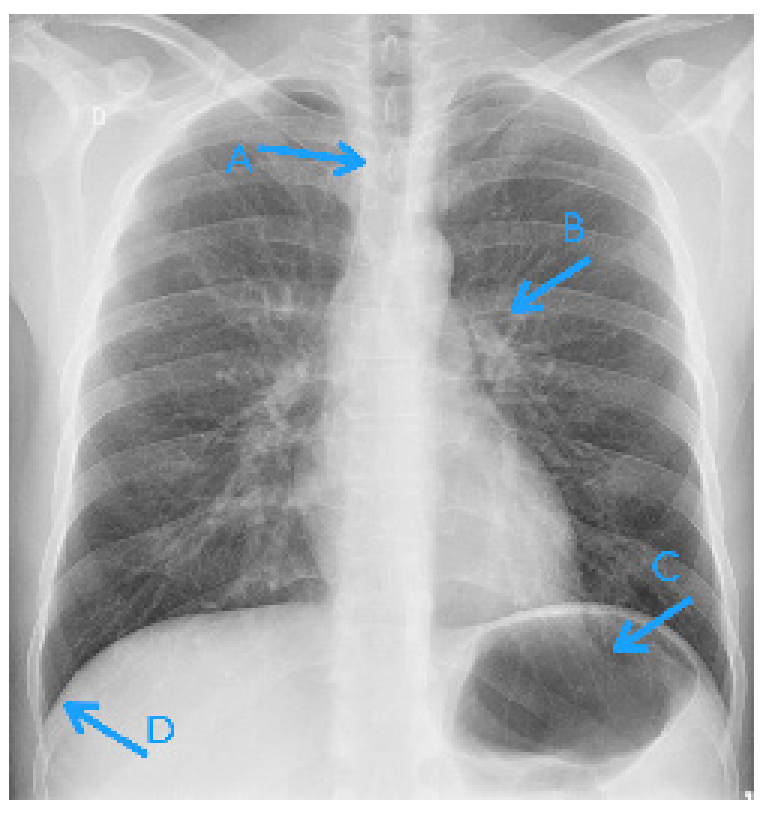
Resposta correta:
A - traqueia
$B$ - hilo pulmonar esquerdo
C - bolha gástrica
$D$ - seio costofrênico direito

4. Qual a definição do lóbulo pulmonar secundário?

Resposta correta: é periférico e delimitado pelos septos interlobulares, é ventilado pelo bronquíolo terminal.

5. Representam variantes anatômicas identificadas no RX de tórax, exceto:
a) Costela cervical
d) Cifoescoliose torácica
b) Calcificações costocondrais
e) Arco aórtico a direita
c) Lobo acessório da veia ázigos

\section{Resposta correta: $d$}




\section{TEXTO 3}

\section{SEMIOLOGIA RADIOLÓGICA E TERMINOLOGIA DA RADIOGRAFIA DE TÓRAX}

1. Cite 3 alterações que levam à redução da atenuação pulmonar no exame radiográfico do tórax.

Resposta correta: Cisto, bolha e cavidade.

2. Em relação à consolidação, indique a alternativa correta:

a) Representa o preenchimento do espaço aéreo ou alveolar

b) Pode indicar alteração extrapulmonar

c) É um tipo de opacidade intersticial

d) Em geral indica um tumor pulmonar central obstrutivo

e) É opacidade densa de limites precisos e contornos regulares

\section{Resposta correta: a}

3. Quais são os quatro padrões de opacidades intersticiais? Cite uma causa para cada.

\section{Resposta correta:}

Padrão reticular - doença intersticial pulmonar fibrosante (fibrose pulmonar idiopática, doença colagenovascular, reação medicamentosa)

Padrão nodular - doença granulomatosa (sarcoidose, silicose, tuberculose)

Padrão septal - edema pulmonar (linfangite carcinomatosa)

Padrão miliar - tuberculose miliar (histoplasmose, metástases)

4. RX de tórax de 2 pacientes diferentes, ambos com doença intersticial pulmonar. Indique quais são as alterações radiográficas de cada caso.

A.

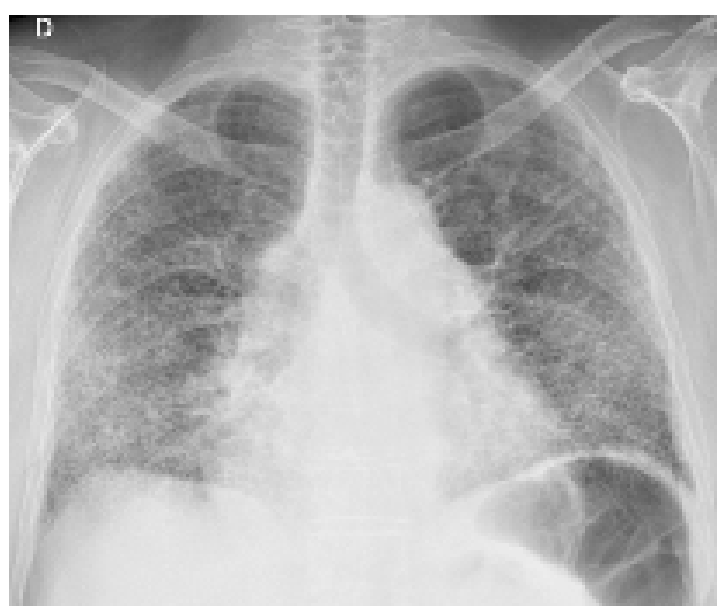

B.

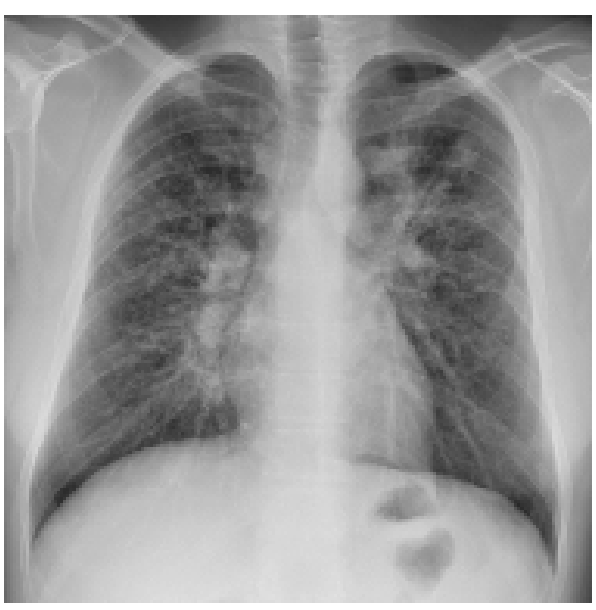

\section{Resposta correta:}

Caso A. Opacidades de padrão reticular com predomínio basal e periférico, sinais de perda de volume pulmonar, aumento da área cardíaca

Caso B. Opacidades de padrão nodular com predomínio superior e central, sinais de hiperinsuflação, aumento do volume hilar por linfonodomegalias 
5. Qual das situações abaixo leva a obliteração do seio costofrênico esquerdo:
a) Linfonodomegalia hilar
d) Derrame ou espessamento pleural
b) Timoma mediastinal
e) Atelectasia do lobo médio

c) $D P O C$

Resposta correta: $d$ 


\section{TEXTO 4}

\section{SINAIS RADIOLÓGICOS NO TÓRAX}

1. São sinais relacionados ao tromboembolismo pulmonar agudo, exceto:
a) Corcova de Hampton
d) Luftsichel
b) Westermark
e) Todos são sinais relacionados ao TEP agudo

c) Palla

\section{Resposta correta: $d$}

2. Qual sinal pode auxiliar na identificação do pneumotórax em uma radiografia em AP?

Resposta correta: Sinal do sulco profundo.

3. Qual o sinal identificado na imagem em PA deste exame de RX de tórax? Qual a provável alteração?
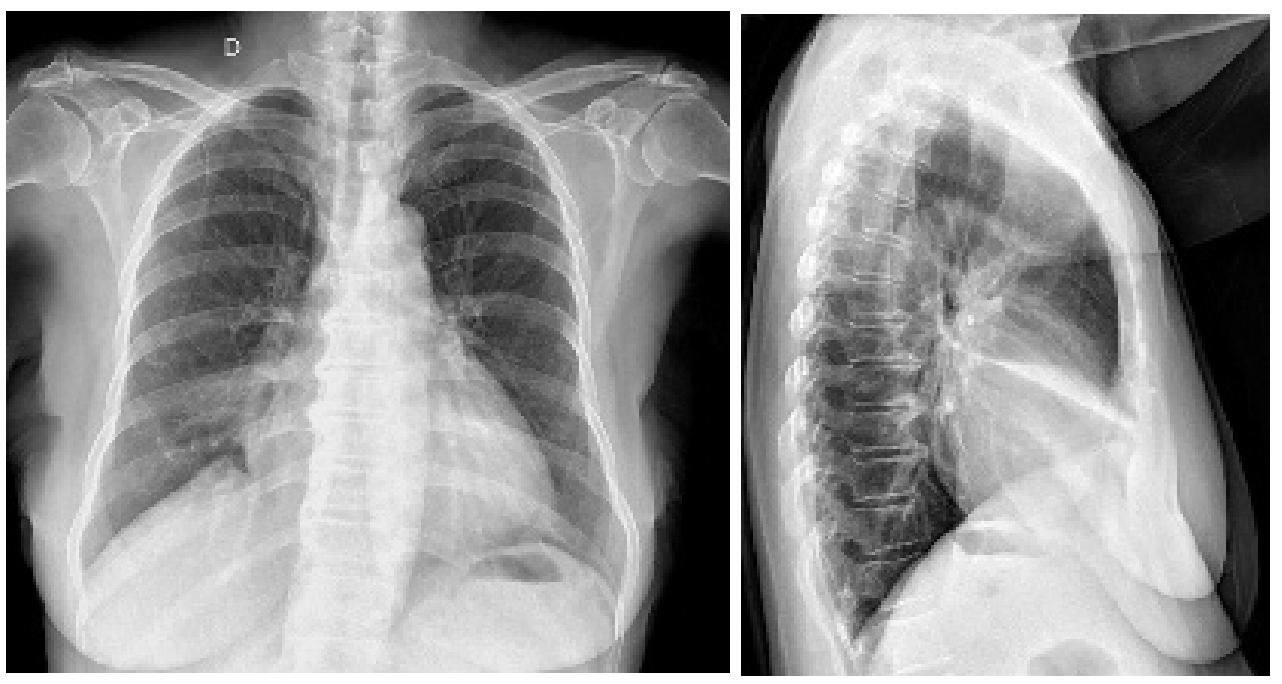

Resposta correta: Há uma consolidação em faixa fazendo sinal da silhueta com a borda cardíaca direita. Representa atelectasia do lobo médio.

4. Qual a diferença de significado entre os sinais da convergência e da sobreposição hilar?

Resposta correta: Convergência hilar indica que a alteração é do hilo pulmonar, enquanto a sobreposição hilar indica que a alteração é extra hilar.

5. Correlacione cada sinal com sua descrição ou significado.
A. Sinal do 1-2-3
D. Split pleura
B. Sinal da cauda de cometa
E. Sinal do crescente aéreo
C. S de Golden

\section{Resposta correta:}

(B) Atelectasia redonda

(C) Neoplasia central obstrutiva

(A) Linfonodopatia paratraqueal e hilar bilateral (sarcoidose)

(E) Bola fúngica

\section{(D) Empiema pleural}




\section{TEXTO 5}

\section{SONDAS, CATETERES E OUTROS APARATOS MÉDICOS}

1. Em relação ao posicionamento do tubo endotraqueal, assinale a alternativa incorreta.

a) O RX deve ser realizado logo após a intubação

b) A cabeça do paciente deve estar em posição neutra

c) A extremidade deve estar a aprox. $5 \mathrm{~cm}$ da carina

d) Intubação seletiva mais comumente ocorre a esquerda

e) A estenose traqueal é complicação tardia

\section{Resposta correta: $d$}

2. Quais as diferenças entre a sonda nasogástrica e nasoentérica?

Resposta correta: Ambas servem para aspiração de conteúdo, administração de medicamentos e nutrição. A sonda nasogástrica deve estar com a extremidade no interior do estômago, além da cardia (abaixo da transição esofagogástrica e diafragma, no estômago tópico), enquanto a sonda entérica deve estar idealmente na segunda porção do duodeno, além da região pilórica, a direita da linha média.

3. Qual aparato médico é identificado neste exame? Inserido por que via? O posicionamento está correto? Por quê?
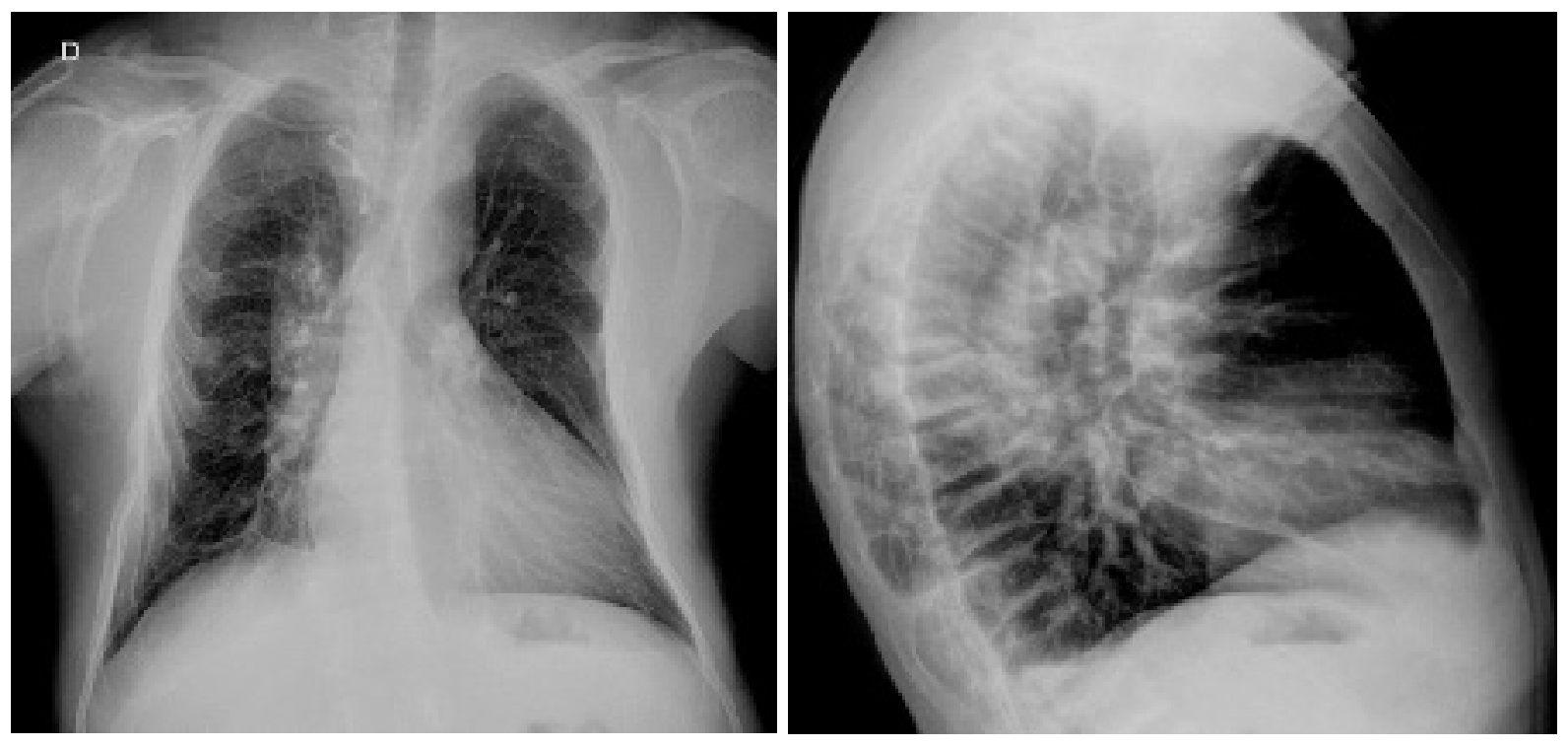

Resposta correta: Identifica-se um cateter de acesso venoso central inserido pela veia subclávia direita, com posicionamento incorreto, pois está dobrado sobre si.

4. Em relação aos dispositivos médicos cardiovasculares, correlacione:
A. Marcapasso cardíaco
D. Balão intra-aórtico
B. $\mathrm{CDI}$
E. Fios de monitorização cardíaca

C. Cateter de Swan-Ganz 


\section{Resposta correta:}

(E) Não confundir com sondas ou cateteres

(D) Ponta radiopaca ao nível do botão aórtico

(A) Dois eletrodos, em átrio e ventrículo direito

(C) Extremidade na região do hilo pulmonar

(B) Um cabo em ventrículo direito

5. Cite três posições inadequadas do dreno torácico.

Resposta correta: Cursando no subcutâneo, em trajeto interfissural ou intrapulmonar. 